\begin{tabular}{|c|c|c|}
\hline & Int.J.Curr.Microbiol.App.Sci (2021) 10(10): 243-251 & \\
\hline & $\begin{array}{l}\text { International Journal of Current Microbiology and Applied Sciences } \\
\text { ISSN: 2319-7706 Volume } \mathbf{1 0} \text { Number } \mathbf{1 0}(\mathbf{2 0 2 1 )} \\
\text { Journal homepage: } \underline{\text { http://www.ijcmas.com }}\end{array}$ & 30 \\
\hline $\begin{array}{l}\text { EXCELLENT } \\
\text { PUBLISHERS }\end{array}$ & & \\
\hline
\end{tabular}

\title{
Bacteriological Profile and Antibiogram of Blood Culture Isolates from Clinically Suspected Septicemic Cases in a Tertiary Care Hospital Shahjahanpur, UP, India
}

\author{
Jitendra Kumar Chaudhary* \\ Department of Microbiology, Varun Arjun Medical College and Rohilkhand Hospital, \\ Banthra, Shahjahanpur, Uttar Pradesh, India \\ *Corresponding author
}

Keywords

Blood stream infections, Bacteremia, Multidrug resistance, Antibiogram

Article Info

Accepted:

10 September 2021 Available Online: 10 October 2021
Blood stream infections mainly by Bacteremia leading to septicemia were the major cause of life threatening sepsis in hospitalized patients. There should be required rapid diagnosis of pathogenic agents and immediate appropriate therapy. These help to decrease of multidrug resistance cases and also morbidity and mortality. During one year period, total 192 blood samples were processed in microbiology laboratory according to standard protocols. Out of 192 samples, 21 were isolated positive and antibiotic sensitivity patterns were performed according to standard CLSI guidelines. The total $10.94 \%$ (21/192) were identified as culture positive of these $66.67 \%$ were Gram negative and $28.57 \%$ Gram positive and $04.76 \%$ Candida species. The gram negative bacteria were predominant isolates. The Klebsiella pneumoniae was $100 \%$ sensitivity to Ceftazidime, Cefepime, Amikacin, Gentamycin and Aztreonam. All nonfermenter isolates were $100 \%$ sensitivity to Ceftazidime, Cefepime, Amikacin, Colistin and Polymyxin-B. Vancomycin sensitivity was seen $100 \%$ to all grams positive isolates. Bacteremia was most common causes of septicemia; the most predominant pathogenic agent was Klebsiella pneumoniae in our study. Surveillance of pathogenic agents and their antibiotics sensitivity pattern should be required to reduce drug resistance and for selection of appropriate therapy.

\section{Introduction}

Bacteremia is defined as the presence bacteria in bloodstream whereas septicemia indicates the presence of microorganism in blood with their toxins and remove by phagocytes. ${ }^{1,2}$ Blood stream infections lead to sepsis is commonly caused by bacteria that are major cause of morbidity and mortality worldwide. Blood stream infections range from selflimiting bacteremia to life threating sepsis requires early diagnosis and immediate treatment. ${ }^{3}$ Blood culture is gold standard test for diagnosis of septicemia which helps to identify the microorganism. In recent year, Gram negative septicemia take over gram 
positive septicemia, among gram negative bacteria the incidence of septicemia are more by the member of Enterobacteriaceae than other gram negative bacilli. Now the sensitivity of bacterial strain of Klebsiella, Pseudomonas and Acinetobacter species are getting multidrug resistant. ${ }^{4,5}$ And also some of Candida species detected in many hospitals in case of neonatal septicemia and ICU patients with prolonged uses of intravascular devices, multiple antibiotics treatment and neoplasia with persistent neutropenia denoted to be independent risk factors for the addition of nosocomial candidemia. ${ }^{6}$

This study was performed to identify the bacterial isolates and antibiotic sensitivity pattern of the isolated bacteria those are useful to clinicians for start off appropriate treatment.

\section{Materials and Methods}

A total 192 blood samples were received for culture of suspected septicemic patients sent by various clinical section at central collection center of Varun Ajun Medical College and Rohilkhand Hospital Shahjahanpur from April 2020 to March 2021.

For adults 7-10 $\mathrm{ml}$ and for children $5 \mathrm{ml}$ Blood samples were collected after taking all antiseptic precautions. For this we tied a tourniquet around the arm then cleaned the skin on the prominent vein site by applying 2 $\%$ iodine and with $70 \%$ Isopropyl alcohol. The blood samples were collected in Brain Heart Infusion (BHI) Broth bottles. For adult's 7-10 $\mathrm{ml}$ blood in $70 \mathrm{ml}$ broth bottle and for children $5 \mathrm{ml}$ blood in $20 \mathrm{ml}$ broth bottle and separately bottles were slightly shaken to mix the sample properly aseptically and then the bottles were incubated at $37^{\circ} \mathrm{c}$ before processing.

After 24 hours if turbidity appears, gram stain was done after making smear from broth bottle directly and communicated the clinician immediately and also subculture was done on the Blood agar, Mac Conkey agar and Saboraud's Dextrose agar. If fungal elements were seen in Gram stain then these growth were inoculated in two plates of Saboraud's Dextrose agar media, one incubated at $37^{\circ} \mathrm{c}$ for 24 hours and other at $25^{\circ} \mathrm{c}$ for 24 hours. After 24 hours all inoculated plates colonies were observed.

If no turbidity appears after 24 hours then blind subculture was done on the Blood agar, MacConkey agar and Saboraud's Dextrose agar and observed next day. If no growths appear in culture media then 3 more subculture was done on alternate days up to total 7 days if again no growth appeared on these 3 subculture media then finally declared as culture negative.

Out of 192 samples only 21 were showed growths on culture media. For identification of bacteria firstly colonies character of growth was observed then Gram stain was done from colonies. On the basis of these the gram positive bacteria or gram negative bacteria was identified. For, further identification had chosen various biochemical tests.

The biochemical tests for gram positive isolates such as Catalase, Coagulase, Mannitol salt agar test, Bacitracin (BC), Optochin (OP) and for gram negative isolates such as Catalase, Oxidase, Indole, Citrate, Urease, Methyl red, Voges-Proskauer, Triple sugar iron test, Motility. ${ }^{7-9}$

Antibiotic sensitivity testing was done by Kirby-Bauer Diffusion method on MullerHintor agar according to CLSI guidelines. ${ }^{10}$ For Gram negative bacteria such as Piperacillin $(100 \mu \mathrm{g})$, moxicillin-clavulanate (20/10 $\mu \mathrm{g}), \quad$ Piperacillin-tazobactam (100/ $10 \mu \mathrm{g})$, Gentamicin $(10 \mu \mathrm{g})$, Amikacin $(30 \mu \mathrm{g})$, Tobramycin $(10 \mu \mathrm{g})$, Doxycycline $(30 \mu \mathrm{g})$, 
Meropenem (10 $\mu \mathrm{g}), \quad$ Imipenem $(10 \mu \mathrm{g})$, Ceftazidime $(30 \mu \mathrm{g}), \quad$ Cefepime $(30 \mu \mathrm{g})$, Cefotaxime $(30 \mu \mathrm{g})$, Ceftriaxone $(30 \mu \mathrm{g})$, Ofloxacin $(5 \mu \mathrm{g})$, Ciprofloxacin $(5 \mu \mathrm{g})$, Colistin $(25 \mu \mathrm{g})$, Aztreonam $(30 \mu \mathrm{g})$ and Cotrimoxazole $(25 \mu \mathrm{g})$. For Gram positive bacteria the antibiotic were used such as, Penicillin (10U), Erythromycin $(15 \mu \mathrm{g})$, Azithromycin $15 \mu \mathrm{g}$, Ciprofloxacin $(5 \mu \mathrm{g})$,

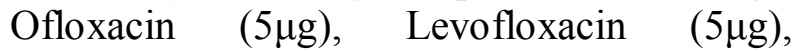

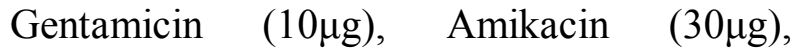
Tobramycin $(10 \mu \mathrm{g})$, Vancomycin $(30 \mu \mathrm{g})$,

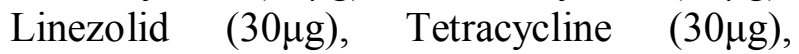
Doxycycline $(30 \mu \mathrm{g})$, Co-trimoxazole $(25 \mu \mathrm{g})$ After that next day antibiotic sensitivity and resistant was interpreted according to CLSI guidelines.

\section{Results and Discussion}

A total of 192 blood samples were collected for blood culture from the clinically suspected cases of septicemia patients and performed during one year period. Of the total 192 blood samples cultured, $10.94 \%$ (21/192) were noted positive growth and $89.06 \%$ (171/192) were noted no growth. Out of the total 21 positive patients, the male patients and female patients were $57.12 \%(12 / 21)$ and $42.87 \%$ (09/21) respectively.

Out of the 21 culture positive samples, more culture growth showed positive from Neonatal intensive care unit (NICU) and Intensive care unit (ICU) Patients, of these 66.67\% (14/21) were Gram negative bacteria and $28.57 \%$ (06/21) Gram positive bacteria and $04.76 \%$ (01/21) Candida species. The gram negative were predominant isolates, Klebsiella pneumonia isolates were $28.57 \% \quad(06 / 21)$ followed by Acinetobacter spp. $19.05 \%$ (04/21), Pseudomonas aeruginosa 19.05\% (04/21), Staphylococcus aureus $14.28 \%$ (03/21), Enterococcus spp. 09.52\% (02/21) and Streptococcus spp. 04.76\% (01/21) (Table $1)$.
For gram negative isolates sensitivity, the Klebsiella pneumonia was $100 \%$ sensitive to Ceftazidime, Cefepime, Amikacin, Gentamycin and Aztreonam but Piperacillin $100 \%$ resistance. Then Cefotaxime, Tobramycin and Doxycycline were 05 $(83.33 \%)$ sensitive whereas, Pipracillintazobactam, Ceftriaxone, Imipenem and Meropenem were 04(66.67\%) sensitive. Cotrimoxazole sensitivity in $03(50 \%)$ and Amoxicillin-clavulanic acid, Ciprofloxacin and Ofloxacin were 01(16.67\%) sensitive only and $05(83.33 \%)$ resistance (Table 2 ).

For non-fermenters, the all non-fermenter isolates were $100 \%$ sensitive to Ceftazidine, Cefepime, Amikacine, Colistin and Polymyxin-B. In these, Pseudomonas aeruginosa was $100 \%$ resistance to Piperacillin followed by03(75\%) sensitivity to Piperacillin-tazobactam, Gentamycin, Imipenem, Meropenem, Aztreonam. But, sensitivity to Tobramycin was $02(50 \%)$ only. Acinetobacter spp. was 03(75\%) sensitive to Piperacillin-tazobactam, Cefotaxime, Ceftriaxone, Imipenem, Meropenem, Tobramycin and Doxycycline. Then, 02(50\%) sensitivity in Amikacin, Co-trimoxazole and 01(25\%) sensitive to Ciprofloxacin (Table 2).

For gram positive isolates, all isolates were $100 \%$ sensitivity to Vancomycin, and all gram positive isolates showed $100 \%$ resistance to Penicillin, Ciprofloxacin, Levofloxacin followed by resistance of Ofloxacin, Azithromycin, Linezolid and Doxycycline were $03(50 \%)$ and Erythromycin, Gentamycin, Amikacin, Tetracycline were 04 $(66.67 \%)$ resistance respectively. Then Cotrimoxazole was $05(83.33 \%)$ resistance (Table 3).

In this study, blood culture positivity of blood stream infection was $10.94 \%$ which are similar to developing countries that is $13.3 \%^{11}$ but in developed countries blood culture 
positive rate is high that is $13.9 \%-29.4 \%$. ${ }^{12,13}$ This present study is comparable to $9.94 \%$ by Manjula et al., $2005^{14}, 10 \%$ by Usha and Pushpa $2007^{17}, 11.2 \%$ by Shalini et al., 2010(18) and $10.8 \%$ by Hamed Ghadhiri et al., $2012^{19}$ at Iran. The differences in developing countries and developed countries to blood culture positivity is due to geographical location, climatic variation, population race, epidemiological variation of etiological agent and variation in infection control policies. ${ }^{20-22}$

In the present study, gram negative isolates were $66.67 \%$ and gram positive isolates were $28.57 \%$. Out of these gram negative isolates, the predominant was Klebsiella pneumoniae $28.57 \%$ followed by Acinetobacter spp. $19.05 \%$, Pseudomonas aeruginosa $19.05 \%$. This finding was in accordance with other studies. $^{23-25}$

The Pseudomonas aeruginosa and Acinetobacter spp. are common pathogen causing nosocomial infection, these are highly resistance to antibiotics led to high morbidity and mortality. ${ }^{23,24,26,27}$

In Enterobacteriaceae, Imipenem and Meropenem were noted $66.67 \%$ sensitive and $33.33 \%$ resistance. This finding was in accordance with the other study. ${ }^{28}$ Above study showed possible appearance of Carbapenem resistance Enterobacteriaceae which indicate towards unreasonable use of carbapenemes. ${ }^{29}$ The Enterobacteriaceae were reported $100 \%$ sensitivityto Amikacin, Gentamycin, Cefepime, Ceftazidime and Aztreonam with better interest towards Cefotazidime, Tobramycin and Doxycyclin were $83.33 \%$ sensitivity. All non-fermenter isolates were $100 \%$ sensitive to Ceftazidime, Cefepime, Amikacin, Colistin and PolymyxinB. Then, for Pseudomonas aeruginosa $100 \%$ resistance to Pipracillin followed by
Piperacillin-tazobactam, Imipenem and Meropenem were $75 \%$ sensitivity, Gentamycin $62.50 \%$ sensitivity and Tobramycin $62.50 \%$ sensitivity. These finding were similar with other studies. ${ }^{27,30}$ In our study, Gram positive isolates were only $28.57 \%$. Out of total isolates the most predominant gram positive isolates was Staphylococcus aureus14-28\%, next one Enterococcus spp. $09.52 \%$ and last one Streptococcus spp. $04.76 \%$ which were comparable with study by Mathur et al., 2014, ${ }^{26}$ who wassolated $14.5 \%$ Staphylococcus aureus followed by 9\% Enterococcus spp. whereas the study by Radha Rani et al., $2017^{31}$ isolates $14.40 \%$ Staphylococcus aureus and $10.14 \%$ Enterococcus spp.

These low isolates of Gram positive bacteria led to increasing of Gram negative pathogens with increasing multidrug resistance and ESBL production, so, there need to apply strict antibiotic policy with importance on antibiotic sensitivity findings (28). In our study, All Gram positive isolates were $100 \%$ sensitivity to Vancomycin and all gram positive isolates showed $100 \%$ resistance to Penicillin, Ciprofloxacin, and Levofloxacin. But, Ofloxacin, Azithromycin, Linezolid and Doxycycline were 03(50\%) resistance only followed by Erythromycin, Gentamycin, Amikacin and Tetracycline were 04(66.67\%) resistance. Then Co-trimoxazole was 05(83.33\%) resistance.

The present study reported Gram negative isolates were predominant organisms causing septicemia. The Amikacin, Cefepime, Ceftazidime, Gentamycin, Piperacillinetazobactam and Carbapenems were established most successful antibiotics for Gram negative isolates. Although Vancomycin, Azithromycin, Linezolid and Doxycycline were established most successful antibiotics for Gram positive isolates. 
Table.1 Table showing various positive isolates from blood cultures (n-21)

\begin{tabular}{|c|c|c|c|}
\hline Microorganism & Isolated microorganism & Number of isolates & Percentage (\%) \\
\hline \multirow{3}{*}{$\begin{array}{c}\text { Gram negative } \\
\text { bacteria }\end{array}$} & Klebsiella pneumoniae & 06 & $28.57 \%$ \\
\cline { 2 - 4 } & Acinetobacter spp. & 04 & $19.05 \%$ \\
\cline { 2 - 4 } Gram positive & Pseudomonas aeruginosa & 04 & $19.05 \%$ \\
\hline bacteria & Staphylococcus aureus & 03 & $14.28 \%$ \\
\cline { 2 - 4 } & Enterococcus spp. & 02 & $09.52 \%$ \\
\cline { 2 - 4 } & Streptococcus spp. & 01 & $04.76 \%$ \\
\hline Fungus & Candida spp. & 01 & $04.76 \%$ \\
\hline
\end{tabular}

Table.2 Antibiotics sensitivity of isolated gram negative bacteria from blood culture (n-14)

\begin{tabular}{|c|c|c|c|}
\hline Antibiotics & $\begin{array}{c}\text { Klebsiella pneumoniae } \\
\text { (06) } \\
\text { (Enterobacteriaceae) }\end{array}$ & $\begin{array}{c}\text { Acinetobacter spp. } \\
\text { (04) } \\
\text { (Non-fermenter) }\end{array}$ & $\begin{array}{c}\text { Pseudomonas aeruginosa } \\
(04) \\
\text { (Non-fermenter) }\end{array}$ \\
\hline Piperacillin & $00(00 \%)$ & - & $00(00 \%)$ \\
\hline $\begin{array}{l}\text { Amoxicillin } \\
\text { clavulanate }\end{array}$ & 01(16.67\%) & - & - \\
\hline $\begin{array}{l}\text { Piperacillin- } \\
\text { tazobactam }\end{array}$ & $04(66.67 \%)$ & $03(75 \%)$ & $03(75 \%)$ \\
\hline Ceftazidime & $06(100 \%)$ & $04(100 \%)$ & $04(100 \%)$ \\
\hline Cefotaxime & $05(83.33 \%)$ & $03(75 \%)$ & - \\
\hline Ceftriaxone & $04(66.67 \%)$ & $03(75 \%)$ & - \\
\hline Cefepime & $06(100 \%)$ & $04(100 \%)$ & $04(100 \%)$ \\
\hline Amikacin & $06(100 \%)$ & $04(100 \%)$ & $04(100 \%)$ \\
\hline Gentamycin & $06(100 \%)$ & $02(50 \%)$ & $03(75 \%)$ \\
\hline Tobramycin & $05(83.33 \%)$ & $03(75 \%)$ & $02(50 \%)$ \\
\hline Imipenem & $04(66.67 \%)$ & $03(75 \%)$ & $03(75 \%)$ \\
\hline Meropenem & $04(66.67 \%)$ & $03(75 \%)$ & $03(75 \%)$ \\
\hline Colistin & - & $04(100 \%)$ & $04(100 \%)$ \\
\hline Polymixin-B & - & $04(100 \%)$ & $04(100 \%)$ \\
\hline Aztreonam & $06(100 \%)$ & - & $02(50 \%)$ \\
\hline Ciprofloxacin & $01(16.67 \%)$ & $01(25 \%)$ & $01(25 \%)$ \\
\hline Ofloxacin & $01(16.67 \%)$ & - & $00(00 \%)$ \\
\hline $\begin{array}{c}\text { Co- } \\
\text { trimoxazole }\end{array}$ & $03(50 \%)$ & $02(50 \%)$ & - \\
\hline Doxycyclin & $05(83.33 \%)$ & $03(75 \%)$ & - \\
\hline
\end{tabular}


Table.3 Antibiotics sensitivity of isolated gram positive bacteria from blood culture (n-06)

\begin{tabular}{|c|c|c|c|}
\hline Antibiotics & $\begin{array}{c}\text { Staphylococcus } \\
\text { aureus }(\mathbf{0 3})\end{array}$ & $\begin{array}{c}\text { Enterococcus spp. } \\
(\mathbf{0 2})\end{array}$ & $\begin{array}{c}\text { Streptococcus spp. } \\
(\mathbf{0 1})\end{array}$ \\
\hline Penicillin & $00(00 \%)$ & $00(00 \%)$ & $00(00 \%)$ \\
\hline Azithromycin & $02(66.67 \%)$ & - & $01(100 \%)$ \\
\hline Erythromycin & $01(33.33 \%)$ & $01(50 \%)$ & $00(00 \%)$ \\
\hline Gentamycin & $02(66.67 \%)$ & - & - \\
\hline Amikacin & $02(66.67 \%)$ & - & $01(100 \%)$ \\
\hline Tetracycline & $01(33.33 \%)$ & $00(00 \%)$ & $01(100 \%)$ \\
\hline Doxycycline & $01(33.33 \%)$ & $01(50 \%)$ & $01(100 \%)$ \\
\hline Vancomycin & $03(100 \%)$ & $02(100 \%)$ & $01(100 \%)$ \\
\hline Linezolid & $01(33.33 \%)$ & $01(50 \%)$ & $01(100 \%)$ \\
\hline Co-trimoxazole & $00(00 \%)$ & - & $00(00 \%)$ \\
\hline Ciprofloxacin & $00(00 \%)$ & $00(00 \%)$ & $00(00 \%)$ \\
\hline Levofloxacin & $00(00 \%)$ & $00(00 \%)$ & $00(00 \%)$ \\
\hline Ofloxacin & $02(66.67 \%)$ & $01(50 \%)$ & - \\
\hline
\end{tabular}

But the increasing rate of multidrug resistance is due to lack of regulation of prescribed antibiotics, which are commonly used in minor illnesses such as sore throat and running nose. These alarm the clinicians and microbiologists for reasonable use of antibiotics, identify appropriate alternate antibiotics and use that alternate antibiotic to prevent the drug resistance.

Bacteremia was the most common causes of septicemia in hospitalized patients. The gram negative bacteria were commonly found in blood stream infection in our study. Among these Klebsiella pneumoniae was the most predominant bacteria causing septicemia. The most common successful antibiotics for Klebsiella pneumoniae were Amikacin, Cefepime, Ceftazidime, Gentamycin, Aztreonambut for non-fermenters Ceftazidime, Cefepime, Amikacin, Colistin and Polymyxin-B were most commonest successful antibiotics. For all Gram positive isolates Vancomycin was most successful antibiotics. This study indicates to increase multidrug resistance septicemia that is more challenging for clinicians and microbiologists.
So, there need early detection of causative agents and their antibiotic sensitivity pattern with regular treatment by appropriate antibiotics without interruption prescribed by clinicians. That will minimize the load of septicemia and also decrease the appearance of more resistance. So, there should be required periodic surveillance of pathogenic agents and their antibiotic sensitivity pattern that direct the selection of appropriate antibiotic for treatment.

\section{Acknowledgments}

I am highly thankful to all the staff of Microbiology department, Varun Arjun Medical College and Rohilkhand Hospital Shahjahanpur for their support.

\section{References}

1. Elmer Koneman, Washington C. Winn, jr.,Stephen allen, Williamjanda. Koneman's color atlas and textbook of diagnostic microbiology, $6^{\text {th }}$ edition. Pageno.97, 2005.

2. Ntusi N, Aubin L, Oliver S, Whitelaw A, Mendelson M. Guideline for the optimal use of blood cultures. SAfrMedJ. 2010; 
100(12):839-843

3. Vanitha R N, Kannan G, Venkata N M, Vishwakanth D, Nagesh V R, Yogitha M, et al., A retrospective study on blood stream infections and antibiotic susceptibility patterns in a tertiary care teaching hospital. IntJPharmPharmSci 2012;4:543-8.

4. Young L S. Sepsis syndrome. In: Mandell G L, Bennet J E, Dolin R, editors. Principle and Practice of Infectious Diseases. Elsevier:Churchill Livingstone;1995.p.690705.

5. Vanitha R N, Kannan G, Venkata N M, Vishwakanth D, Nagesh V R, Yogitha M, et al., A retrospective study on blood stream infections and antibiotic susceptibility patterns in a tertiary care teaching hospital. IntJPharmSci 2012;4:543-8.

6. Shilpi Gupta, Bineeta Kashyap. Bacteriological profile and antibiogram of blood culture isolates from a tertiary care hospital of North India. Tropical J. Medical research. Vol.19.Issue.2.Jul-Dec2016,94-99.

7. Reinhart K, Daniels R, Kisson N, Machado F R, Schachter R D, L L Band Finfer S. Recognising sepsis as a global health priority: A WHO resolution. N Engl J Med. 2017; 377: 414-417. Doi:10:1056/NEJMp1707170.

8. Cruickshank K, Duguid J P, Marmion B P. Test for sensitivity to microbial agents. In:Medical Microbiology. Chuchill Livingstone, 1980; 190-209.

9. Cheesbrough, M. District laboratory practice in tropical countries. 2.Vol.2.Cambridge, UK:Cambridge

University press;2000.p.124-5.

10. Murray B, P Faller, T. Manual of Clinical Miceobiology.6. American Society of Microbiology Press; Washington DC:1999.

11. Clinical and Laboratory Standards Institute (CLSI). $20^{\text {th }}$ Informational Supplement. Wayne, PA:CLSI;2012. Performance Standards for Antimicrobial Susceptibility Testing. CLSI document M100-S20.

12. Shrestha S, Amatya R, Shrestha R K, Shrestha R. Frequency of blood culture isolates and their antibiogram in a teaching hospital.

NepalMedAssoc.2014;52(193):692-7.

13. Panday R S N, Wang S, Ven $P$ M V D, Hekker T A M, Alam N, Nanayakkara P W B. Evaluation of blood culture epidemiology and efficiency in a large European teaching hospital. PLoSOne2019;14(3):e0214052.

14. Sorsa A, Fruh J, Stotter L, Sileshi A. Blood culture result profile and antimicrobial resistance pattern: are port from NICU, Asella teaching and referral hospital, Asella, South East Ethiopia. Antimicrobial resistance and infection control 2019;8(42). Doi:10:1186/513756-019-0486-6.

15. Manjula M, Pyria D, Varsha G:Antimicrobial susceptibility pattern of blood isolates from a teaching Hospital in north India. Japan J Infec Dis 2005, 58:174176.

16. Usha A, Pushpa D (2007) Bacterial profile of blood stream infections and antibiotic resistance pattern of isolates. JKSci9(4):186190.

17. Shalini S, Kranthi K, Gopalkrishna B K. The microbiological profile of nosocomial infections in the intensive care unit. $\mathbf{J}$ ClinDiagnRes 2010; 4: 3109-12.

18. Hamed Ghadiri, 1 Hamid Vaez, 2 Samira Khosravi, 3 and Ebrahim Soleymani 3. The Antibiotic Resistance Profiles of Bacterial Strains Isolated from Patients with HospitalAcquired Blood stream and Urinary Tract Infections. Care Research and Practice Volume 2012, Article ID 890797.

19. Kalpesh Gohel, Amit Jojera, Shailesh Soni, Sishir Gang, Ravindra Sabnis, and Mahesh Desai Bacteriological Profile and Drug Resistance Patterns of Blood Culture Isolates in a Tertiary Care Nephrourology Teaching Institute BioMed Research International, Volume2014, 5pages, 2014, doi:10.1155/2-014/153747.

20. Araya G. Wasihun, Letemichael N. Wlekidan, Senay A. Gebremariam, Tsehaye A. Dejene A. L. Welderrufael, T. D. Haile and saravanan Muthupand-ian. Bacteriological profile and antimicro-bnial patterns of blood culture isolates among febrile patients in Mekelle Hospital, 
Northern Ethiopia. SpringerPlus (2015)4:314.

21. Dagnew M, Yismaw Getal. Bacterial profile and antimicrobial susceptibility pattern insepticemia suspected patients attending Gondar University Hospital, North west Ethiopia. BMCResNotes.2013; 6: 283.

22. Vanitha R N, Kannan G, Venkata N M, Vishwakanth D, Nagesh V R, Yogitha M, et $a l$. A retrospective study on blood stream infections and antibiotic susceptibility patterns in a tertiary care teaching hospital. IntJPharmSci 2012;4:543-8.

23. Shilpi Gupta, Bineeta Kashyap. Bacteriological profile and antibiogram of blood culture isolates from a tertiary care hospital of North India. Tropical J. Medical research. Vol.19.Issue.2.Jul-Dec2016,94-99.

24. Nidhi Pal and Ramamurthy Sujatha, Microbiological Profile and Antimicrobial Resistant Pattern of Blood Culture Isolates, Among Septicaemia Suspected Patients. National Journal of Laboratory Medicine.2016 Jan, Vol5(1): 17-21.

25. Mathur P, Varghese P, Tak V, Gunjiyal J, Lalwani S, Kumar S, Misra M C. Epidemiology of blood stream infections at a level-1 trauma care center of India. J LabPhysicians2014; 6:22-7.

26. Chhina D, Gupta V. Bacteriological profile and antimicrobial susceptibility pattern of
Blood isolates from a tertiary care hospital in North India.IJPRBS2013; 2:24-35.

27. Leonid M Irenge, Landry Kabego, Faustin B Kinunus, Rapheal B Chirimwami. Antimicrobial resistance of bacteria isolated from patients with blood stream infections at a tertiary care hospital in the Democratic Republic of the Congo. SAMJ.Sept.2015,Vol.105,No.9;752-755.

28. Poirel I, Revathi G, Bernabeu S, etal., Detection of NDMI producing Kleibsiella pneumoniain Kenya. Antimicrobagent'schemother 2011: 55(2): 954-936.

29. Datta S, Wattal C, Goel N, J. K. Raveendran, Prasad K. J.(2012) “ A ten year analysis of Multi-drug resistant Blood stream infections caused by E.coli \& Klebsiella pneumonia in a tertiary care hospital," Indian Journal of Medical Research, 135 (6)907-12.

30. Radha Rani D, Sridevi Chaitanya B, Senthil J, Basanth Kumar R, Krishna Prabhakar K, Krishna Mohan M V T, Vibhavani Nayak K, Pravan Kumar, Ayyagari Santa and $T$ Subramanyeshwara Rao. Retrospective analysis of blood stream infections and antibiotic susceptibility pattern of Gram negative bacteria in a tertiary care career hospital. IJMRHS,2017: 6(12): 19-26.

\section{How to cite this article:}

Jitendra Kumar Chaudhary. 2021. Bacteriological Profile and Antibiogram of Blood Culture Isolates from Clinically Suspected Septicemic Cases in a Tertiary Care Hospital Shahjahanpur, UP. Int.J.Curr.Microbiol.App.Sci. 10(10): 243-251. doi: https://doi.org/10.20546/ijcmas.2021.1010.029 